\title{
Tobacco and cigarette butt consumption in humans and animals
}

\author{
Thomas E Novotny, ${ }^{1}$ Sarah N Hardin, ${ }^{1}$ Lynn R Hovda, ${ }^{2}$ Dale J Novotny, ${ }^{3}$ \\ Mary Kay McLean, ${ }^{4}$ Safdar Khan ${ }^{4}$
}

${ }^{1}$ Graduate School of Public Health, San Diego State University, San Diego, California, USA

${ }^{2}$ SafetyCall International, PLLC and Pet Poison Helpline, Bloomington, Minnesota, USA ${ }^{3}$ San Diego State University Research Foundation, San Diego, California, USA ${ }^{4}$ ASPCA Animal Poison Contro Center, Urbana, Illinois, USA

\section{Correspondence to}

Professor Thomas E Novotny, Graduate School of Public Health, San Diego State University, Hardy Tower 119, 5500 Campanile Drive, San Diego, CA 92186, USA; tnovotny@mail.sdsu.edu

Received 5 February 2011 Accepted 7 February 2011

\section{UN IOCKAD}

This paper is freely available online under the BMJ Journals unlocked scheme, see http:// tobaccocontrol.bmi.com/site/ about/unlocked.xhtml

\section{ABSTRACT}

Discarded cigarette butts may present health risks to human infants and animals because of indiscriminate eating behaviours. Nicotine found in cigarette butts may cause vomiting and neurological toxicity; leachates of cigarette butts in aquatic environments may cause exposure to additional toxic chemicals including heavy metals, ethyl phenol and pesticide residues. This report reviews published and grey literature regarding cigarette butt waste consumption by children, pets and wildlife. Although reports of human and animal exposures number in the tens of thousands, severe toxic outcomes due to butt consumption are rare. Nonetheless, the ubiquity of cigarette butt waste and its potential for adverse effects on human and animal health warrants additional research and policy interventions to reduce the stream of these pollutants in the environment.

\section{INTRODUCTION}

Cigarette butt waste is not only unsightly, but when ingested may be hazardous to the health of humans and animals. Cigarette butts are commonly discarded onto beaches, sidewalks, streets, parks and many other public places where children, domestic animals and wildlife may be exposed to risk of ingestion; they may also be accessed by children from ashtrays at home, in cars or in public places. When carelessly discarded by smokers, they are carried from storm sewers and beaches to streams and waterways leading directly to the aquatic environment. ${ }^{1}$ Infants, as well as many sea creatures, birds and pets are indiscriminate eaters, and ingested plastic trash, including cigarette butts, can choke an animal or poison it with toxins. Animals may not be able to regurgitate such items, with some acquiring gastrointestinal bezoars that can lead to a false sense of satiation and subsequent under-nutrition. ${ }^{2}$ However, canines often self-decontaminate through vomiting.

Cigarettes contain at least 4000 chemicals, with about 50 of these being carcinogenic. ${ }^{3}$ Many of these chemicals are derived from agricultural use in tobacco growing, including herbicides, insecticides, fungicides and rodenticides; humectants may be added to keep tobacco moist. Many are additives used in flavouring and adjusting the burn rate of cigarettes, and the tobacco industry has reported many of these as being 'generally regarded as safe'-when consumed as food, but not necessarily when combusted and then consumed. ${ }^{4}$ Cigarette butts have been shown to leach out numerous chemicals such as heavy metals, nicotine and ethylphenol in water and may be a continual point source for contamination of aquatic environments after discarding. ${ }^{5}$ One laboratory-based study has shown that cigarette butt leachates can kill water fleas (Daphnia species) in relatively low concentrations. ${ }^{6}$ Slaughter et al demonstrated that the median lethal dose is approximately one cigarette butt per litre of water for both freshwater and saltwater test fish species. ${ }^{7}$

Approximately $0.6-3.0 \%$ of tobacco (by dry weight) is composed of nicotine, a plant pesticide, although it is no longer used as such in the USA. Nicotine is the most commonly reported toxic substance causing symptoms among children who have consumed cigarettes or butts. Although a typical cigarette contains from $9 \mathrm{mg}$ to $30 \mathrm{mg}$ of nicotine, inhalation through smoking is only about 0.5-2 $\mathrm{mg}$ per cigarette. The estimated toxic dose of nicotine in non-addicted adults is $4-8 \mathrm{mg}$, and the lethal dose after one-time ingestion among children is reported as 40-60 mg. ${ }^{9}$ Nicotine in tobacco products is rapidly absorbed by oral and intestinal mucosa, and alkalinisation enhances absorption; nicotine-related symptoms develop rapidly ( $<4$ hours) after ingestion. ${ }^{10}$ These may represent a wide variety of symptoms including nausea, vomiting, salivation and diaphoresis; with severe poisoning, there may be convulsions, bradycardia with hypotension, cardiac arrhythmias and respiratory depression.

Cigarette butts have a bitter taste, and thus this may limit the amount of nicotine that is accidentally ingested. However, children often explore their environment through oral contact or through mimicry of adult behaviours. ${ }^{11}$ In young children, 1-2 mg may be toxic, causing nausea and vomiting in low doses, and more extensive neurological symptoms with higher doses. ${ }^{12}$

In pets, an oral minimum lethal dose of nicotine in dogs is reported to be $9.2 \mathrm{mg} / \mathrm{kg}$; however, clinical signs have been reported at doses as low as $1 \mathrm{mg} / \mathrm{kg}$. In small dogs, signs can be seen after the ingestion of one cigarette. ${ }^{13}$ With large ingestions, dogs may have a very poor prognosis as a result of nicotine toxicity. ${ }^{14}$ Pet birds are particularly sensitive to many chemicals owing to their small size and very efficient metabolism. Curious birds have been reported to ingest cigarette butts left in household ashtrays and have died as a result. ${ }^{15}$

In order to evaluate the potential extent of cigarette and butt ingestion among animals and humans, we present a brief summary of ingestion reports from published and grey literature, as well as results of a brief online survey of the Cigarette Butt Pollution Project (CBPP) contacts who might be involved in wild animal rescue and monitoring. 
We also report data from two national veterinary poison control resource centres.

\section{Methods}

First, we searched published material using the PubMed database to identify reports on cigarette butt ingestion by humans or animals. Second, boolean searches were conducted using http:// google.com for "cigarette butt ingestion", "my dog ate a cigarette", "animals that eat cigarette butts", "child poisoning" and "child cigarette ingestion". Published material found on the web search was retrieved from the San Diego State University library databases. Next, we posted a request on the CBPP website (http://www.cigwaste.org) seeking information from website visitors regarding cigarette butt ingestion by wildlife or pets. We then used SurveyMonkey, ${ }^{16}$ a free online market research tool, to seek information by email from CBPP voluntary contacts regarding cigarette butt ingestion by marine animals including birds, mammals, turtles and fish. This survey consisted of 10 questions asking whether the volunteers had worked with marine animals and had observed ingested cigarette butts; if they had any specific knowledge of reports on animals ingesting cigarette butts; and if they knew of cigarette butts found on necropsies of recovered animals. The survey allowed open-ended responses to refer to other individuals, organisations or reports. In addition, specific information was sought from the San Diego Zoo pathology database involving recovered wildlife and zoo animals' necropsy reports. Finally, co-authors (MKMcL and LRH) provided data from the ASPCA Animal Poison Control Center (AAPC), Urbana, Illinois, and the Pet Poison Help Line $(\mathrm{PPH})$, Bloomington, Minnesota, on reported cigarette and cigarette butt ingestion from 2005 to 2010.

\section{RESULTS}

\section{Cigarette butt consumption by humans}

Reports of accidental ingestion of cigarettes (and butts) are not uncommon among children, especially those $<6$ years old. Most reports and reviews of cigarette and butt ingestion have described few significant toxic responses or sequelae among children to cigarette or butt consumption (table 1), but some have shown severe toxicity with as few as two cigarettes consumed. ${ }^{17}$

Some concern was raised ${ }^{22}$ about the possible differences between European and American tobacco's nicotine content because the two studies reporting more severe observed toxicity were European (in Greece and Italy). Malizia et al ${ }^{9}$ described four children who ingested two cigarettes each and developed salivation, vomiting, diarrhoea, tachypnoea, tachycardia and hypotension within 30 minutes, and depressed respiration and cardiac arrhythmias within 40 minutes. Convulsions occurred within 60 minutes of ingestion. All recovered after gastric lavage with activated charcoal, intermittent positive pressure ventilation and intravenous diazepam for convulsions. In addition, one older prospective study ${ }^{17}$ also reported toxicity among four of five children (aged 20 months-9 years) consuming from half to four pieces of nicotine gum.

In a review of 20 cases of 'cigarette tobacco' ingestion by children $\leq 2$ years of age in Wisconsin, ${ }^{19} 13$ children were treated with emetics and activated charcoal, and only one child was symptomatic enough to require hospitalisation. In Philadelphia, the Albert Einstein Hospital Emergency Department described 700 children $<6$ years old who ingested cigarettes or cigarette butts and reported to the Poison Control Centre in 1988-91. ${ }^{18}$ Of these, $143(20.4 \%)$ were symptomatic, and vomiting was the only symptom in 138 (98.6\%), occurring in <20 minutes in 104 (74.3\%). In 1997, the Rhode Island Department of Health reported 146 cases of cigarette butt ingestion among children $<6$ years old; of these, approximately one-third displayed transient nicotine toxicity. ${ }^{21}$ During 2001 to 2006, 276 children presented at the Japan Red Cross Hospital with cigarette ingestion. ${ }^{23}$ The majority of these were $<1$ year old, and $83 \%$ were asymptomatic and thus treated with only observation.

Based on the population-representative National Electronic Injury Surveillance System of the US Consumer Product Safety Commission, Quirk ${ }^{24}$ reported approximately 12000 total cigarette injuries in 2002-7. Of these, about 4400 (one-third) were listed as 'ingestion' or 'poisoning'. The other most common diagnoses were burns (43\%) and bruises or abrasions (12\%). From 2006 to 2008, the American Association of Poison Control Centers (AAPCC) reported nearly 14000 injuries caused by tobacco products among children, $70 \%$ of whom were $<6$ years old. Most of these exposures (90\%) were due to the ingestion of cigarettes or cigarette butts. ${ }^{25}$ The vast majority of these incidents were non-toxic and the children were not hospitalised.

A recent study of new, flavoured, dissolvable, candy-like smokeless tobacco products ${ }^{26}$ provided further information regarding accidental consumption. Connolly et al analysed 13705 tobacco product ingestion cases reported to the National Poison Data System for 2006-8, most (70\%) of which were among infants $<1$ year of age. Smokeless tobacco products were the second most common tobacco products ingested by children, after cigarettes and used filter tips, and increased in proportion with increasing age. Further regulatory review of these new products was recommended.

\section{Cigarette butt consumption by pets and wildlife}

Reports of nicotine ingestion in domestic animals are rare; however, this ingestion can cause excessive salivation, excitement, tremors, vomiting, lack of coordination, weakness,

Table 1 Reports of cigarette and butt ingestion among children, 1983-2009

\begin{tabular}{|c|c|c|c|c|c|c|}
\hline Study site and author & Year & No & Age & $\%$ Symptomatic & $\%$ Hospitalised & Comments \\
\hline Italy (Malizia, 1983) $^{9}$ & 1983 & 4 & $?$ & 100 & 100 & Severe toxicity, including convulsions \\
\hline USA (Smolinske, 1988) ${ }^{17}$ & 1988 & 51 & 5 months -2.5 years & $\begin{array}{l}26 \% \text { of } 19 \text { butt } \\
\text { ingestion cases }\end{array}$ & 0 & $\begin{array}{l}\text { Dose response, starting with one cigarette } \\
\text { consumed }\end{array}$ \\
\hline Philadelphia (McGee, 1995) ${ }^{18}$ & $1988-91$ & 700 & Mean 12 months & $\begin{array}{l}20.4(>90 \% \\
\text { vomiting) }\end{array}$ & $<1$ & $\begin{array}{l}\text { One with nicotine toxicity, observational } \\
\text { therapy only }\end{array}$ \\
\hline Wisconsin (Bonadio, 1989) ${ }^{19}$ & 1988 & 20 & $<2$ years & 50 & 5 & One with nicotine toxicity, induced vomiting \\
\hline Greece (Petridou, 1995) ${ }^{20}$ & 1995 & 15 & $2-4$ years & 100 & 100 & $\begin{array}{l}\text { Vomiting and tachycardia, gastric lavage and } \\
\text { charcoal }\end{array}$ \\
\hline Rhode Island (CDC, 1997) ${ }^{21}$ & $1994-6$ & 146 & Mean 11.6 months & 33 & 0 & Minor toxic effects \\
\hline Long Island (Sisselman, 1996) ${ }^{22}$ & $1993-5$ & 223 & $<6$ years & 18 & 0 & No gastric lavage indicated, observation only \\
\hline Japan (Kubo, 2008) ${ }^{23}$ & $2001-6$ & 276 & Median 1 year & 17 & $<1$ & No lavage, observation for 2 hours \\
\hline
\end{tabular}


Table 2 Reported cigarette and cigarette butt ingestions by domestic animals, USA, 2005-10*

\begin{tabular}{lccllll}
\hline Species & $\begin{array}{l}\text { Cigarette and butt } \\
\text { ingestion calls }(\mathbf{n})\end{array}$ & $\begin{array}{l}\text { No symptomatic } \\
\text { at time of call (\%) }\end{array}$ & $\begin{array}{l}\text { Age range } \\
\text { (years) }\end{array}$ & Weight range $(\mathbf{k g})$ & $\begin{array}{l}\text { Dose range } \\
(\mathbf{m g} / \mathbf{k g}) \dagger\end{array}$ & $\begin{array}{l}\text { Mortality } \\
(\mathbf{n})\end{array}$ \\
\hline Avian & 2 & 0 & $1-8$ & Unknown and $0.5 \mathrm{~kg}$ & 45 & 0 \\
Canine & 801 & $363(45.3)$ & $0.1-16$ & $2-105 \mathrm{lb}$ & $0.08-142$ & $1 \neq$ \\
Caprine & 2 & 0 & 1 & 27.1 & 11 & 0 \\
Feline & 41 & $11(26.8)$ & $0.1-15$ & $1.98-9.0$ & $1.69-170$ & 0 \\
Rodent & 1 & $1(100)$ & 1 & 0.5 & Unknown & 0 \\
Turtle & 1 & $1(100)$ & 15 & 3.6 & 1.9 & \\
\hline
\end{tabular}

*Sources: Pet Poison Help Line, Bloomington, MN and ASPCA Animal Poison Control Center, Urbana, IL.

†ASPCA data only.

‡Euthanised case assessed by ASPCA veterinarian as doubtful owing to toxicity (time, findings and history not consistent with exposure).

convulsions, respiratory failure and even death. ${ }^{27} 28$ There are only anecdotal reports of wild animals (sea turtles) ingesting cigarettes butts. ${ }^{29}$ No reports of cigarette butt ingestion were found on a review of the San Diego Zoo Necropsy Database (C Witte, personal communication 1 December 2010).

Over the period 2005-10, the PPH and the APCC received calls on 801 cases of cigarette or butt ingestion among dogs, on 41 among cats and on six among other animal species (table 2). Animals ingesting multiple items other than cigarettes or butts or those in multi-animal households were excluded from the $\mathrm{PPH}$ database analysis. Follow-up data were unavailable on some of the ingestions from $\mathrm{PPH}$, but most symptomatic cases involved gastrointestinal signs (primarily retching and vomiting) and neurological signs such irritability, lethargy or ataxia. Ingestion ranged from one cigarette or butt to an ashtray full of butts and a pack of cigarettes.

According to the APCC, in canine cases that were assessed by APCC staff as highly likely to be due to tobacco ingestion (time, clinical finding, history are sufficient and characteristic of a toxicosis from the agent) or medium likely (findings are characteristic, but historical and/or clinical data not completely available), $55 \%$ of patients had vomiting and $25 \%$ of patients were ataxic after ingestion. Other common signs included lethargy, tremors, hypersalivation and bradycardia. Ingestion ranged from one to 30 cigarette butts.

Only 14 responses were received from the SurveyMonkey procedure. Of these, none reported finding cigarette butt ingestion in a sick or dying animal. When asked "Do you see cigarette butt waste as a major environmental concern, and if so, why or why not," only four responded affirmatively. Selected openended responses included: "I see so much of it in our environment", "(concern) due to quantities and harm" and "During a two mile cardio walk I usually pick up over 100 of them, but I do not know the impact on wildlife".

\section{DISCUSSION}

This review suggests that cigarette butt consumption by small children and animals is a frequent source of concern and attention for poison control centres, parents and pet owners. The ubiquity of this waste should thus be a concern for policymakers who would seek to reduce the costs of dealing with tobacco ingestions for both parents and providers. We found that severe poisoning by cigarette butts among young children was rare but possible and that poison centres already emphasise the need to reduce the risk of poisoning by tobacco products. ${ }^{30}$ It is clear that smokers must treat cigarette butts as toxic waste products and take more care in discarding them; children will mimic parental behaviour by putting these items into their mouths and sometime consume them in quantities sufficient to be toxic. It is also clear that new, flavoured tobacco products are a source of concern for poisoning among small children because these products, unlike cigarette butts, are not foul tasting.

Veterinary reports of nicotine poisoning are uncommon, but domestic animals may consume them and show serious gastrointestinal, central nervous system and cardiovascular signs. Veterinary poison centre data may be further studied with regard to follow-up on reported exposures and outcomes of these exposures.

We have not yet been able to identify well-documented reports of cigarette butt consumption by wildlife. However, this does not mean that such consumption does not occur. On the other hand, cigarette and butt consumption among domestic animals is fairly common and of concern to pet owners. It would logically follow that wild animals might also be at risk of butt consumption in natural environments. Our brief email survey and web-based appeal for information were very limited by lack of structure, response and a non-representative sampling design.

Future survey research on knowledge, attitudes and practices involving cigarette butt waste should be conducted systematically, possibly through key informant surveys or even population-based surveys of smokers and non-smokers. There is substantial and growing evidence about the toxicity of cigarette butt leachates in aquatic environments, but more research is needed to ascertain specific toxic substances in cigarette butt leachates, their bioaccumulation potential and chemical markers of cigarette butt waste in natural settings.

Given the precautionary principle for environmental hazards, ${ }^{31}$ the potential harm to children, pets and wildlife caused by cigarette butt waste in the environment should be recognised. This concern might be addressed by holding accountable tobacco producers for costs incurred for medical care expenditures caused by butt consumption by children and animals and for mitigation of cigarette butt waste in the environment. $^{32}$

Acknowledgements The authors are grateful to the Pet Poison Help Line, the ASPCA Animal Poison Control Center and the San Diego Zoo for providing access to their data on animal consumption of tobacco products.

Funding This research was funded by the California Tobacco-Related Diseases Research Program Grant \#17IT-0014.

Competing interests None.

Contributors TEN conceived of this article, invited co-authors, supervised researchers involved, wrote the penultimate draft.

Provenance and peer review Not commissioned; not externally peer reviewed.

\section{REFERENCES}

1. Novotny TE, Lum K, Smith E, et al. Cigarettes butts and the case for an environmental policy on hazardous cigarette waste. Int $J$ Environ Res Public Health 2009;6:1691-705. 
2. Ocean Conservancy. Marine Debris: More Than an Eye Sore. Washington, DC: Ocean Conservancy, 2008. http://www.oceanconservancy.org/site/DocServer/ Marine Debris finalrevise.pdf?doclD=4504 (accessed 21 Nov 2010).

3. U.S. Department of Health and Human Services. The Health Consequences of Smoking: A Report of the Surgeon General. Atlanta, GA, USA: US Department of Health and Human Services, Centers for Disease Control and Prevention, National Center for Chronic Disease Prevention and Health Promotion, Office on Smoking and Health, 2004.

4. Harris B. The intractable cigarette 'filter problem'. Tob Control 2011;20(Supp 1): i9-i15.

5. Moerman JW, Potts GE. Analysis of metals leached from smoked cigarette litter Tob Control 2011:20(Supp 1):i28-i32.

6. Micevska T, Warne M, Pablo F, et al. Variation in, and causes of, toxicity of cigarette butts to a cladoceran and microtox. Arch Environ Contam Toxicol 2006:50:205-12

7. Slaughter $\mathbf{E}$, Gersberg R, Watanabe $\mathrm{K}$, et al. Toxicity of cigarette butts, and their chemical components, to marine and freshwater fish. Tob Control 2011;20(Supp 1):i23-i27.

8. Hoffmann D, Hoffmann I. Chemistry and toxicology. In: Department of Health and Human Services, National Cancer Institute, Cancer Control and Population Sciences. Bethesda, MD, USA: U.S. Smoking and Tobacco Control Monograph No. 9, 1998:55-104.

9. Malazia M, Andreucci G, Alfani F, et al. Acute intoxication with nicotene alkaloids and cannabinoids in children from ingestion of cigarettes. Hum Toxicol 1983;2:315-16.

10. Hulzebos CV, Walhof C, de Vries TW. Accidental ingestion of cigarettes by children [Abstract]. Ned Tijdschr Geneeskd 1998;142:2569-71.

11. Johnson CP, Blasco PA. Infant growth and development. Pediatr Rev 1997; 18:224-42.

12. Salomon ME. Nicotine and tobacco preparations. In: Goldfrank LR, Nelson LS, Howland MA, et al, eds. Goldfrank's Toxicologic Emergencies. 8th edn. New York, NY: McGraw-Hill, 2006:1221-30.

13. Spoo W. Nicotine Toxicosis. In: Bonagura J, ed. (XIV) Kirk's Current Veterinary Therapy. 2008:135-8.

14. Hackendahl NC, Sereda CW. Toxicology brief: the dangers of nicotine ingestion in dogs. Veterinary Med 2004:218-24.

15. Sakas PS. Keeping Your Bird Healthy-Basic Pet Bird Care Part I, Article II, Section H. 2007. http://www.gccbc.org/ARTICLES/articles.htm. (accessed Retrieved on Nov 21, 2010)
16. Survey Monkey. http://www.surveymonkey.com/?cmpid=eng:us:ps:googleggclid= CIWJy6zJ8qYCFVBe2godG1v-Bg.

17. Smolinske SC, Spoerke DG, Spiller SK, et al. Cigarette and nicotine chewing gum toxicity in children. Hum Toxicol 1988;7:27-31.

18. McGee D, Brabson T, McCarthy J, et al. Four-year review of cigarette ingestions in children. Pediatr Emerg Care 1995;11:13-16.

19. Bonadio WA, Anderson Y. Tobacco ingestions in children. Clin Ped 1989;28:592-3.

20. Petridou E, Polychronopolou A, Kouri N, et al. Childhood poisoningsfrom ingestion of cigarettes. Lancet 1995:346:1296.

21. CDC. Ingestion of cigarettes and cigarette butts by children - Rhode Island, January 1994-July 1996. Morb Mortal Wkly Rep 1997:46:125-8.

22. Sisselman SG, Mofenson HC, Caraccio TR. Childhood poisonings from ingestion ofCigarettes. Lancet 1996;12:200-1.

23. Kubo K, Chishiro T. Six-year review of cigarette ingestion in children-gastric lavage versus medical observation [Abstract]. Chūdoku kenkȳu 2008:21:115-22.

24. Quirk JT. Cigarette-related injuries to young children in the USA, 2002-2007. Public Health 2009;123:628-9.

25. Bronstein AC, Spyker DA, Cantilena JR, et al. 2007 Annual Report of the American Association of Poison Control Centers' National Poison Data System (NPDS) Clin Toxicol 2008:46:927-1057.

26. Connolly GN, Richter P, Aleguas A, et al. Unintentional child poisonings through ingestion of conventional and novel tobacco products. Pediatrics 2010;125:896-9.

27. Vig MM. Nicotine poisoning in a dog. Vet Hum Toxicol 1990:32:573-5.

28. Kaplan B. Acute nicotine poisoning in a dog. Vet Med Small Anim Clin 1968:63:1033-4.

29. Stanley K, Stabenau E, Landry A. Debris ingestion by sea turtles along the Texas coast. In: Schroeder BA, ed. Eighth Annual Workshop on Sea Turtle Conservation and Biology. Fort Fisher, NC, USA: NOAA Technical Memorandum, 1988:119-21.

30. California Poison Control System. Top 10 Ways to Keep Children Safe from Poison. San Francisco: University of California. http://www.calpoison.org/public/ top_10_prevent.pdf (accessed 21 Nov 2010).

31. United Nations Environment Program. Rio Declaration on Environment and Development. http://www.unep.org/Documents.multilingual/Default.asp? DocumentID=78\&ArticleID=1163 (accessed 5 Feb 2011)

32. Product Stewardship Institute. Extended Product Responsibility State Laws as of October 2010. http://www.productstewardship.us/displaycommon.cfm? an $=1$ \&subarticlenbr $=280$ (accessed 28 Oct 2010)

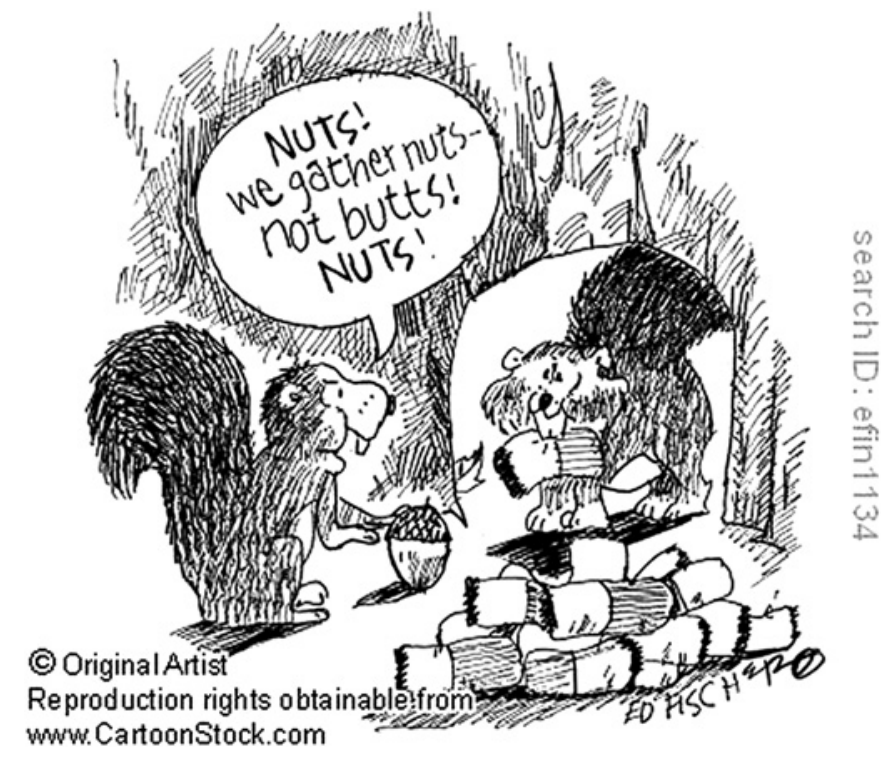

